\title{
TWO CASES OF SUB-ACUTE HEPATIC NECROSIS
}

\author{
BY
}

\author{
HAZEL H. CHODAK GREGORY, M.D., M.R.C.P., \\ Physician for Diseases of Children, Royal Free Hospital ; \\ Physician, East London Hospital for Children, London.
}

The two following cases of hepatic necrosis in children seem to be worth recording: one for its extreme youth ( 8 months) and its wholly puzzling ætiology ; and the other for its apparent connection with epidemic catarrhal jaundice.

\section{Case reports.}

Case 1.-A girl baby, aged 8 months, was brought to the East London Hospital for Children with the complaints that the abdomen had been swelling and that the child was occasionally yellow. She had had broncho-pneumonia, not severely, six weeks previously, and before that had been perfectly well. She was the first child of a young couple, aged 20 and 21 respectively, both healthy. There had been no miscarriages; she was born at full term and weighed $9 \frac{1}{4} \mathrm{lb}$. at birth, was being breast-fed entirely and had gained weight steadily until her illness.

On admission the child was found to be well developed and well nourished, weighing 15 lb. $12 \mathrm{oz}$. She looked very pale with a sub-icteric tinge, though with no icterus of the scleræ. No teeth. No sign of rickets in epiphyses. Chest normal.

The abdomen was protuberant, with some enlarged veins in the wall, running from groin to thorax. The liver was much enlarged, the edge being below the umbilicus ; it was hard and firm, no nodules could be felt and it was evidently not tender. The spleen was also enlarged, firm and smooth; its tip was at the level of the umbilicus. Urine: no albumin, sugar, pus or bile; not tested for urobilin. Blood : red blood corpuscles 2,390,000 per c.cm., hæmoglobin 48 per cent., white blood corpuscles 20,000 , fragility of red cells normal. Mantoux reaction negative.

Wassermann reactions were tried on more than one occasion, and Kahn once. They gave the following results :-

Jan. 2lst. Baby doubtful positive. Mother negative. Father negative.

Feb. 1lth. Baby negative.

Feb. 18th. Baby positive after a small dose of sulpharseno-benzine.

Feb. 18th. Baby Kahn reaction positive.

Course.-During the first four weeks the child was in hospital there was no improvement in the general condition. Such jaundice as had been present disappeared, but the anæmia increased. A week after admission both kidneys could be felt behind the enlarged liver and spleen, a fact which further complicated the diagnosis, as they were evidently much swollen. The glands of the neck and axillæ also became somewhat enlarged. The size of the spleen diminished; the liver remained enlarged and the abdominal veins became more dilated.

Owing to the doubtful Wassermann test in the first instance, a repetition was made after a provocative dose of sulpharseno-benzine, with a positive result; the Kahn test was also positive. On this result it was decided to institute anti-syphilitic treatment; accordingly the child was given mercury and iodide, together with injections of sulpharseno-benzine. In the light of later events it would seem that this course was probably unwise and not only added complexity 
to the diagnosis but possibly hastened the end by contributing another poison, namely arsenic, to the over-burdened liver. The absence of any other signs of syphilis in the infant, together with the clean history sheet of the first few months of life, were of more importance on the negative side than a complement-fixation test on the positive side.

The child lived about two months in hospital, that is probably between three and four months altogether from the onset of symptoms. During the week before death the temperature was raised, otherwise the disease had been afebrile.

Autopsy.-The liver was enlarged and stained greenish yellow. The surface was finely nodular, the nodules varying in size from a pin's head to a small pea, somewhat flattened and at no point very prominent. The liver substance did not feel hard and cut without resistance. The cut surface showed much bile staining, the lobular arrangement was lost, completely in some parts, partially in others, and there was an appearance of new fibrous tissue irregularly arranged.

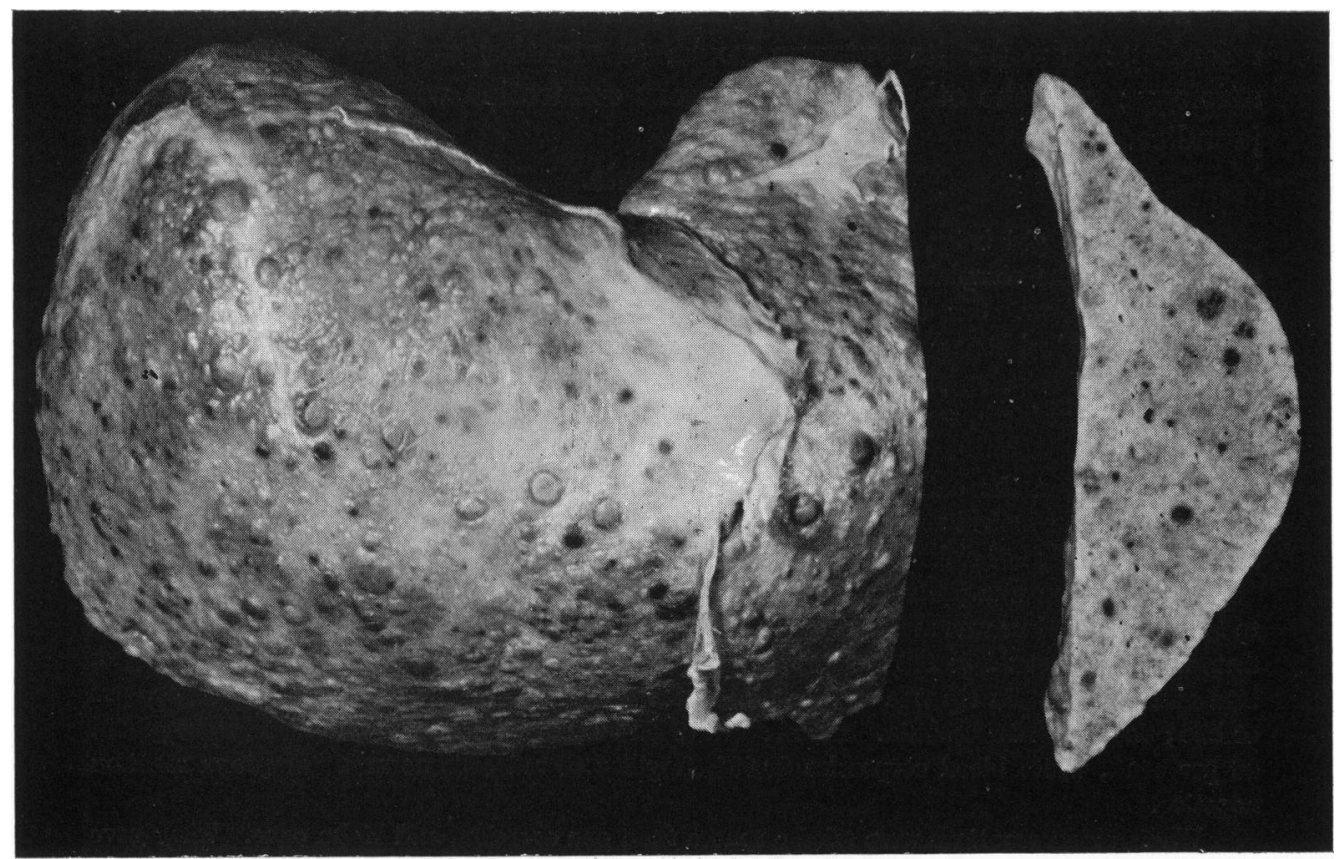

Fig. 1. Case 1. Liver with cross section.

The spleen was enlarged but showed no gross changes. Both kidneys were much enlarged, about one and a half times the normal size, were pale, and showed general swelling of both cortex and medulla.

Microscopically, the destruction of liver cells was irregular in distribution; even in those parts of the organ where necrosis was at a minimum there was considerable fibro-cellular infiltration and an interference with the lobular arrangement. In the areas of maximum destruction very few liver cells remained, and none in orderly arrangement. There were chiefly masses of fibro-cellular tissue, isolated cells and innumerable sprouting bile-ducts defining either old or regenerating lobules. The latter showed vigorous but evidently unsuccessful attempts at hyperplasia, as most of the new cells were loaded with fat. Levaditi staining showed no evidence of syphilis in the liver. The kidneys showed much swelling and degenerative changes of the parenchyma. The lymphatic glands of neck and axillæ, which had been enlarged for a period during life, had returned to normal size. There were no changes in the lungs, heart or brain. 


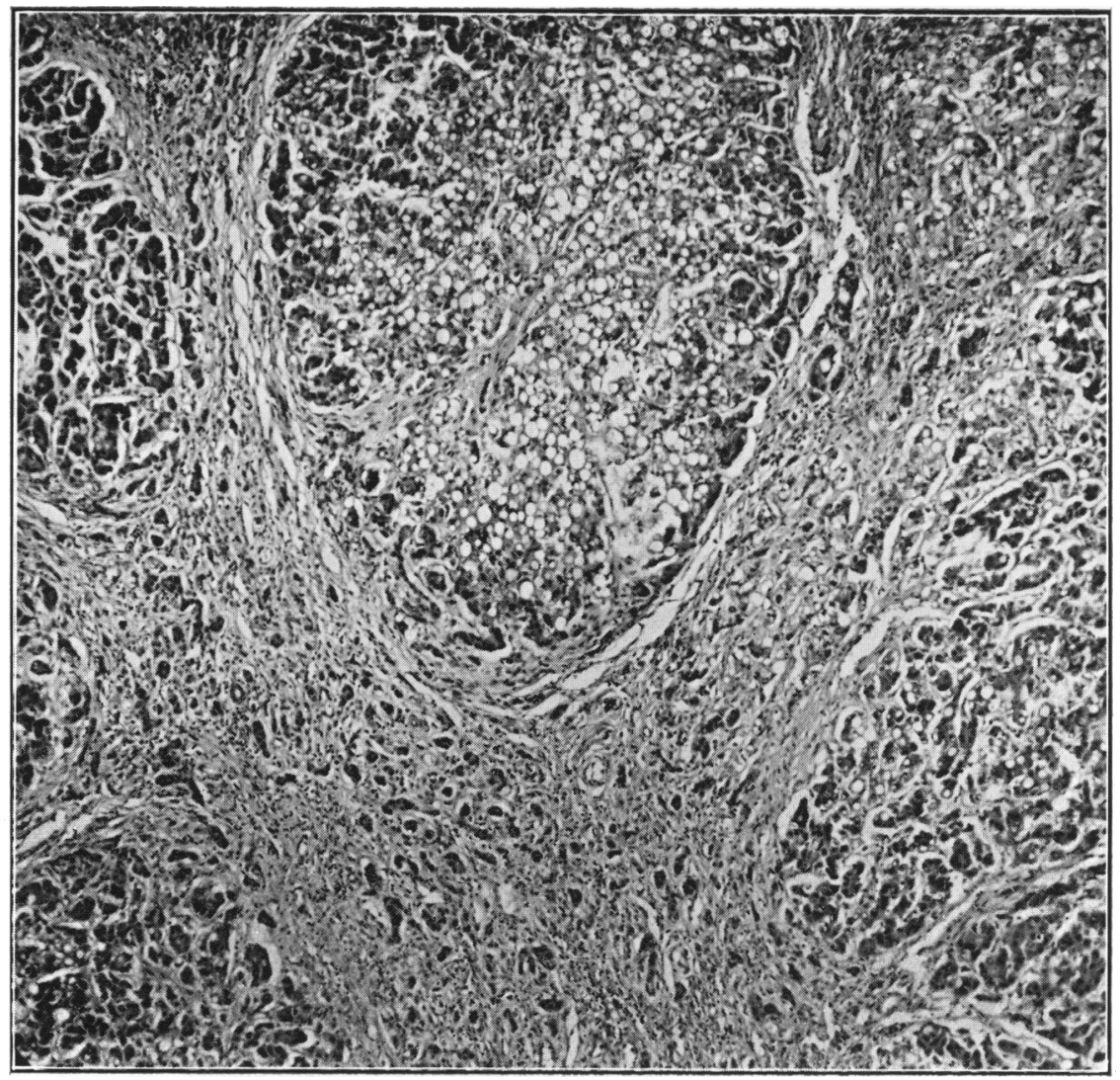

FI(: 2. Case 1. (Low power). Regeneration nodule on surface of liver, showing much fatty change and embedded in fibro cellular matrix rich in sprouting bile-ducts and isolated parenchvma.
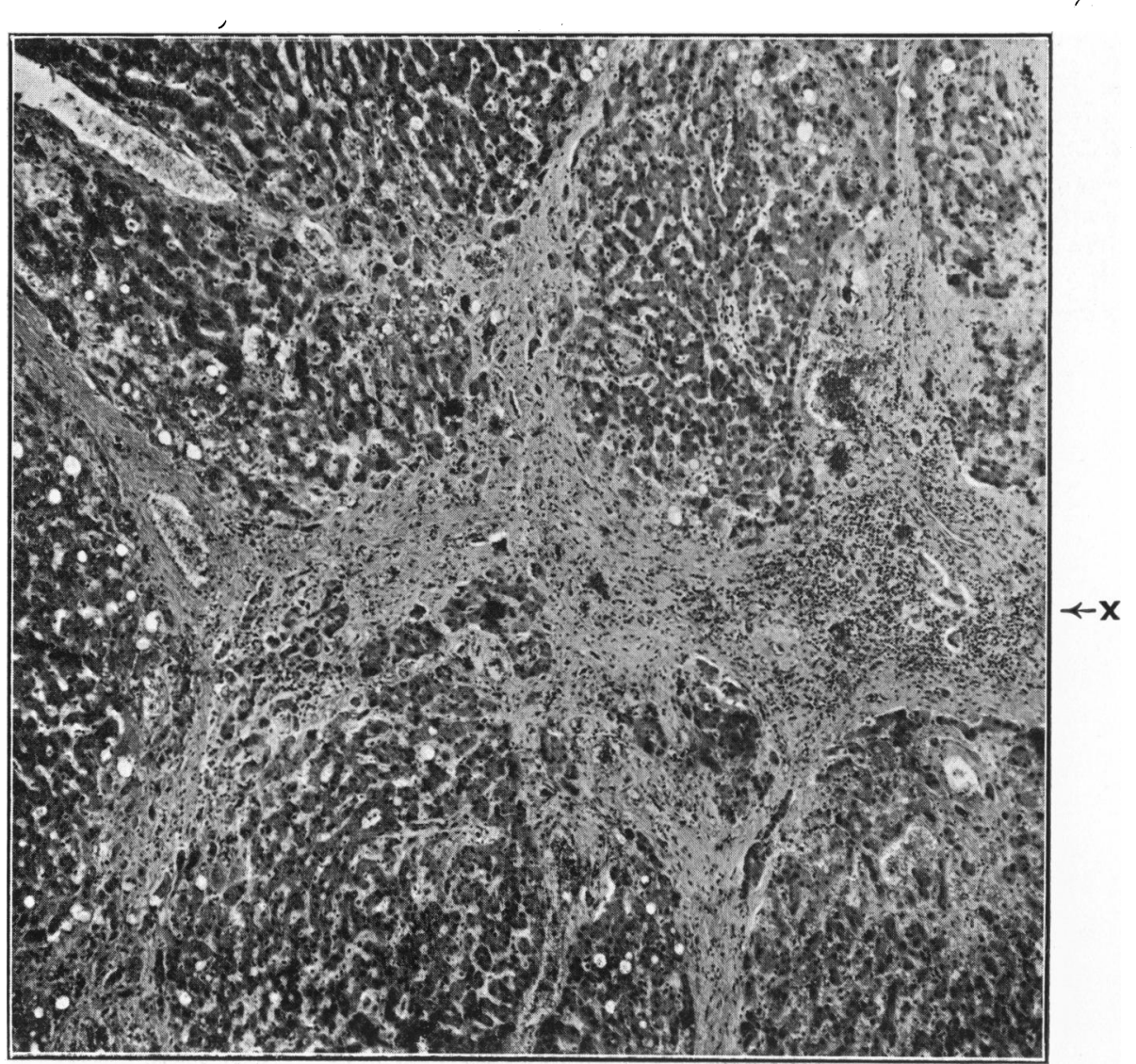

Fig. 3. Case 1. General low power view of part of liver whose destruction was minimal. Consideratle orderly regeneration. Suggestion of active process at $\mathbf{X}$ 


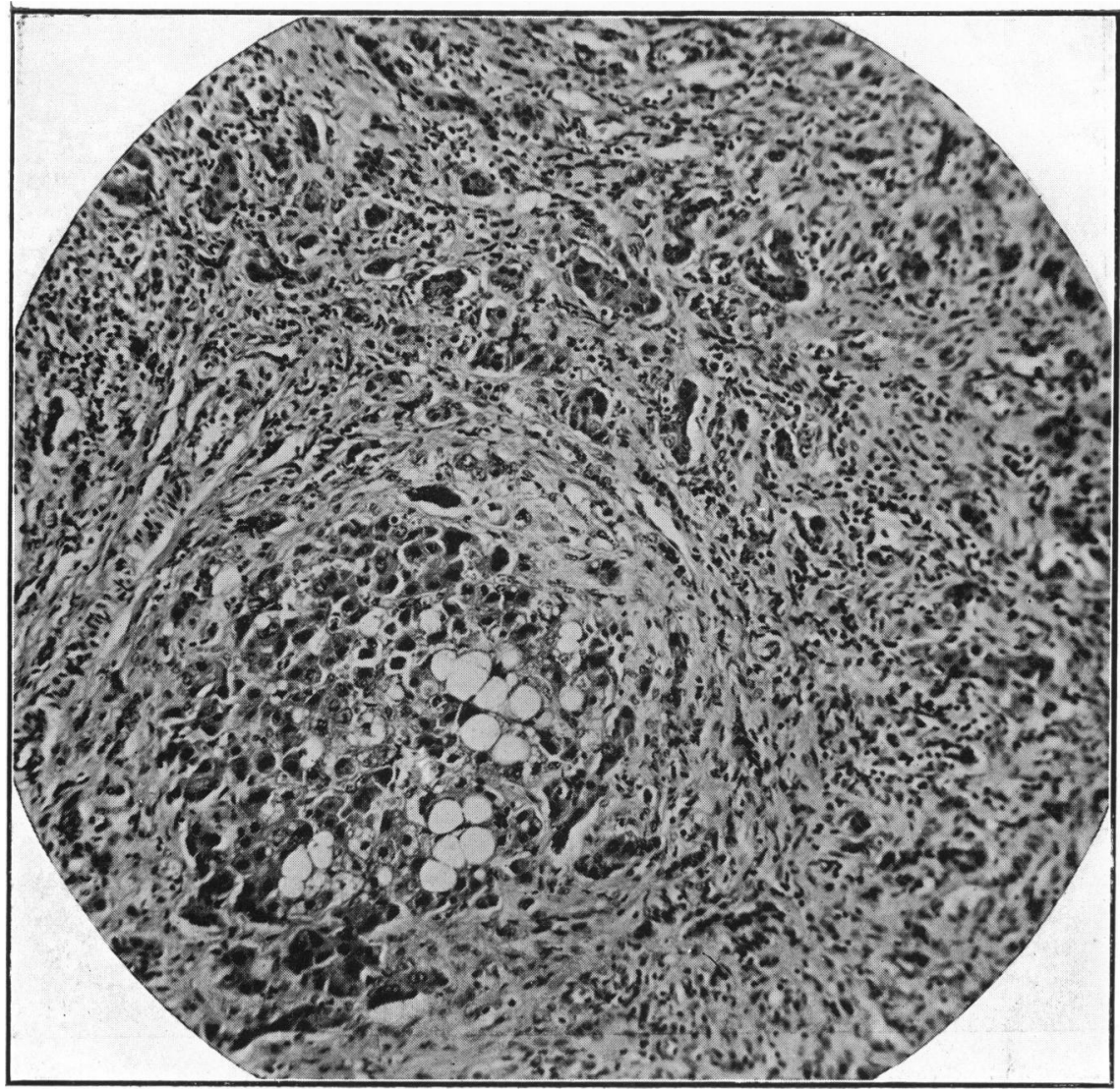

Fır. 4. Case 1. High power detail.

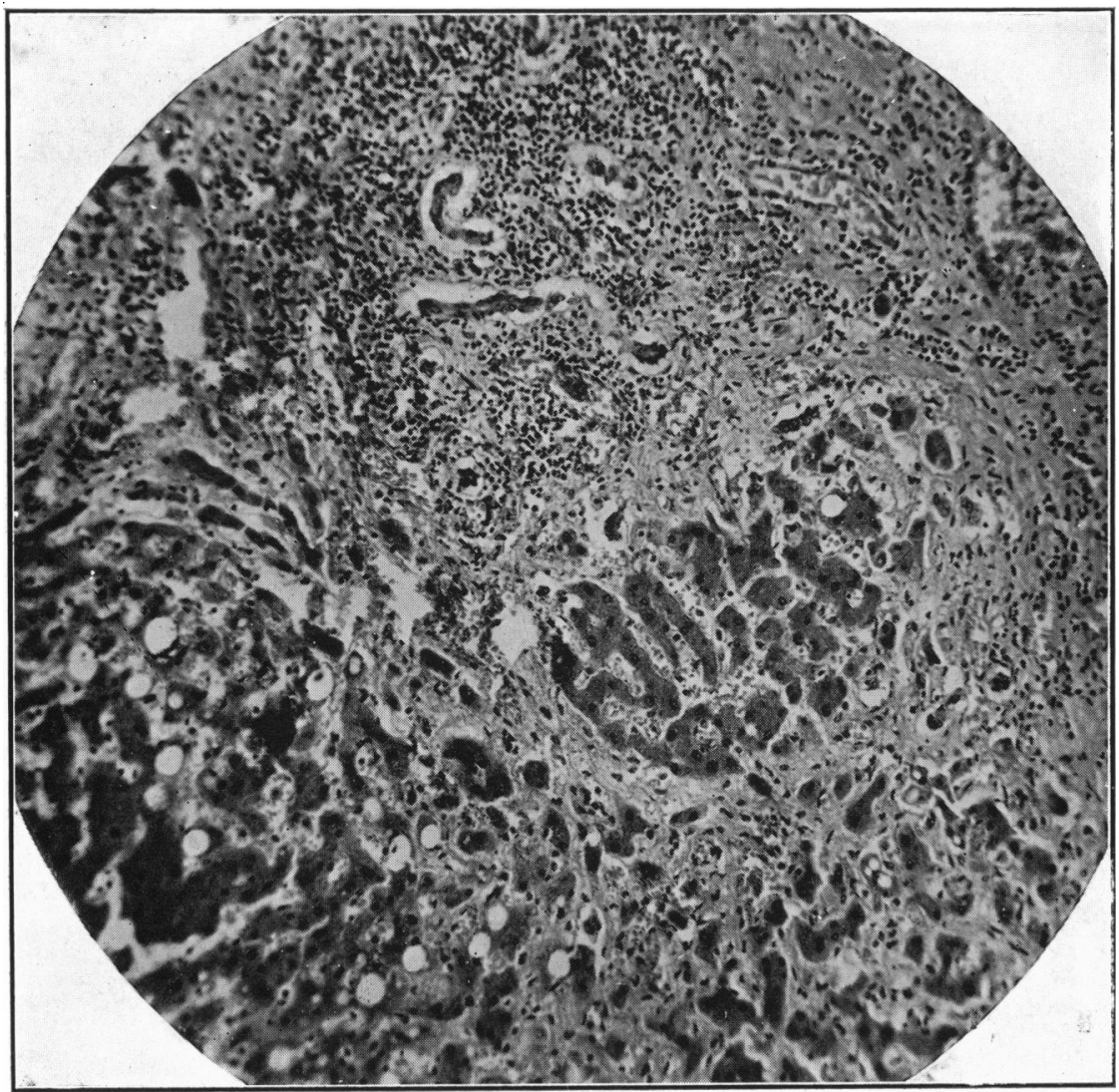

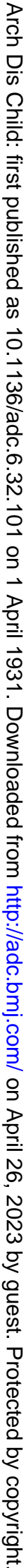

FIt*. 5. Case 1. High power detail. 
Case 2.-A girl, aged 2 years, was brought to the Royal Free Hospital with complaints of vomiting 8 days and jaundice 4 days before admission. The urine had been dark and the motions frequent, loose and grey. There was general irritability of temper. One day after the onset her left ear had started to discharge. A brother aged 7 years had had a slight attack of jaundice a few weeks previously and was now well. A careful enquiry subsequently discovered no other point that could be helpful in the ætiology, except that the child was very fond of bright-coloured sweets.

On admission the temperature was $99^{\circ}$, pulse 120 , respirations 24 . The child was irritable and cried incessantly. The jaundice was moderately deep ; the liver was enlarged to $1 \frac{1}{2}$ inches below the costal margin in the mammary line. Stools were clay-coloured and urine dark with

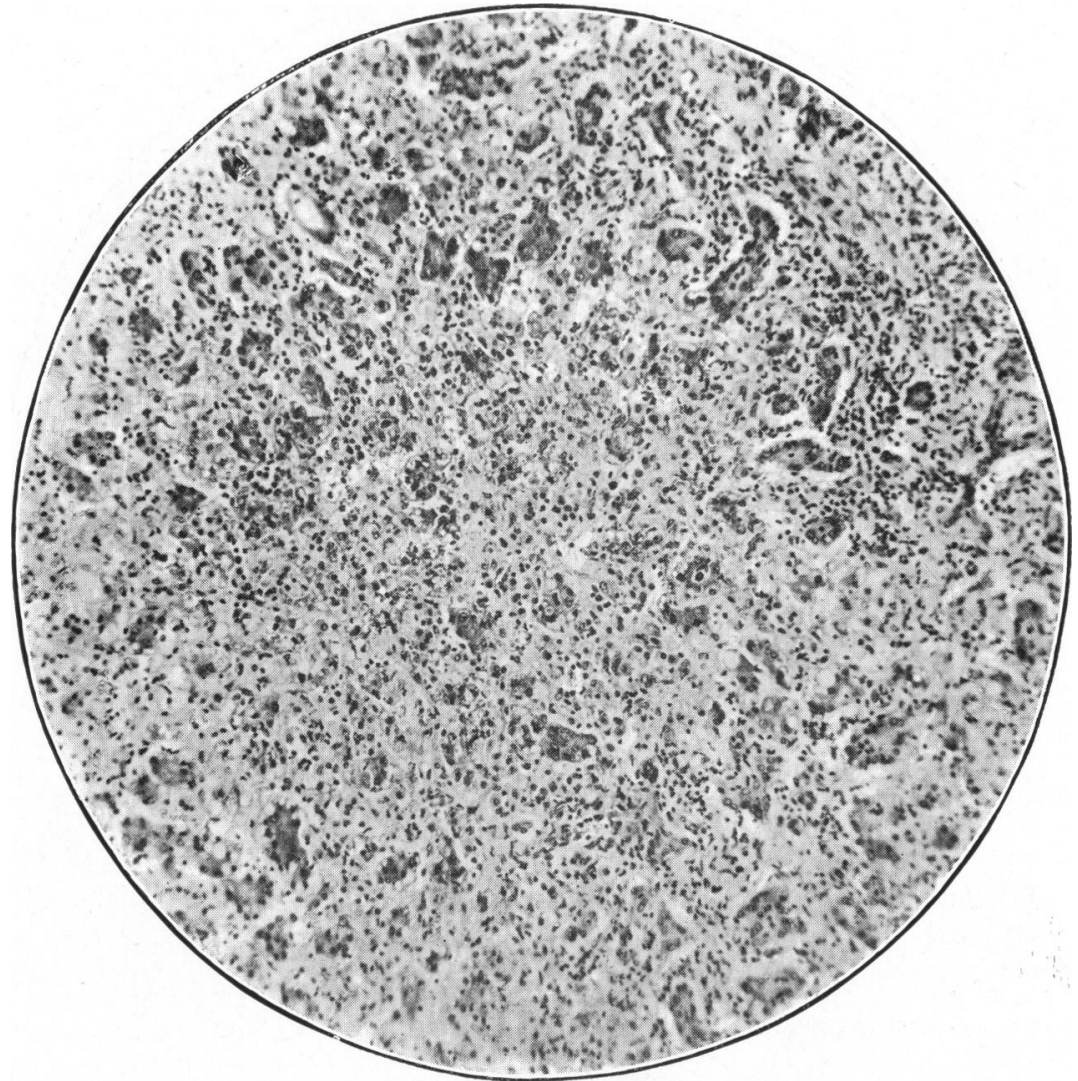

Fic: 6. Cage 2. Showing complete destruction of parenchyma, and abundant new growth of bile ducts.

bile. The left ear was discharging freely. The case was diagnosed as one of catarrhal jaundice, probably epidemic, as her brother had had jaundice recently.

Courss- About 10 days after admission, however, it became evident that it was not running a straight forward course. The jaundice deepened, the liver became slightly more enlarged, the child was still excessively irritable; both ears were now discharging blood and pus. There was no pyrexia ; indeed the temperature had been subnormal since the first day of admission. On the 2lst day after illness she suddenly became rigid and semi-conscious, and exhibited Cheyne-Stokes breathing. Her blood count on this day was as follows : Red blood corpuscles 5,390,000 per c.mm., hæmoglobin 84 per cent., colour index $\cdot 8$, white blood corpuscles 45,600 per c.mm., of which polymorphonuclears were 88.5 per cent., platelets 308,000 . Fragility began at $\cdot 38$ per cent. $\mathrm{NaCl}$, finished at $\cdot 3$ per cent. 
The cerebro-spinal fluid was bile-stained, but otherwise normal and not under pressure. In the afternoon she had a hæmatemesis, followed by convulsions, coma and death.

Autopsy.-A well-nourished child with jaundice of skin and conjunctivæ, and some septic spots round about ears.

The dura mater was bile-stained and firmly adherent in the middle fossa. There was no evidence of extension of inflammation from the middle ears which both contained pus.

Liver slightly enlarged, pale and firm; on section it felt exceedingly tough like rubber. It was dirty yellow in colour with small punctate reddish areas, and the normal pattern was completely lost. The gall-bladder was hyperæmic and contained viscid white bile, the bile ducts were patent.

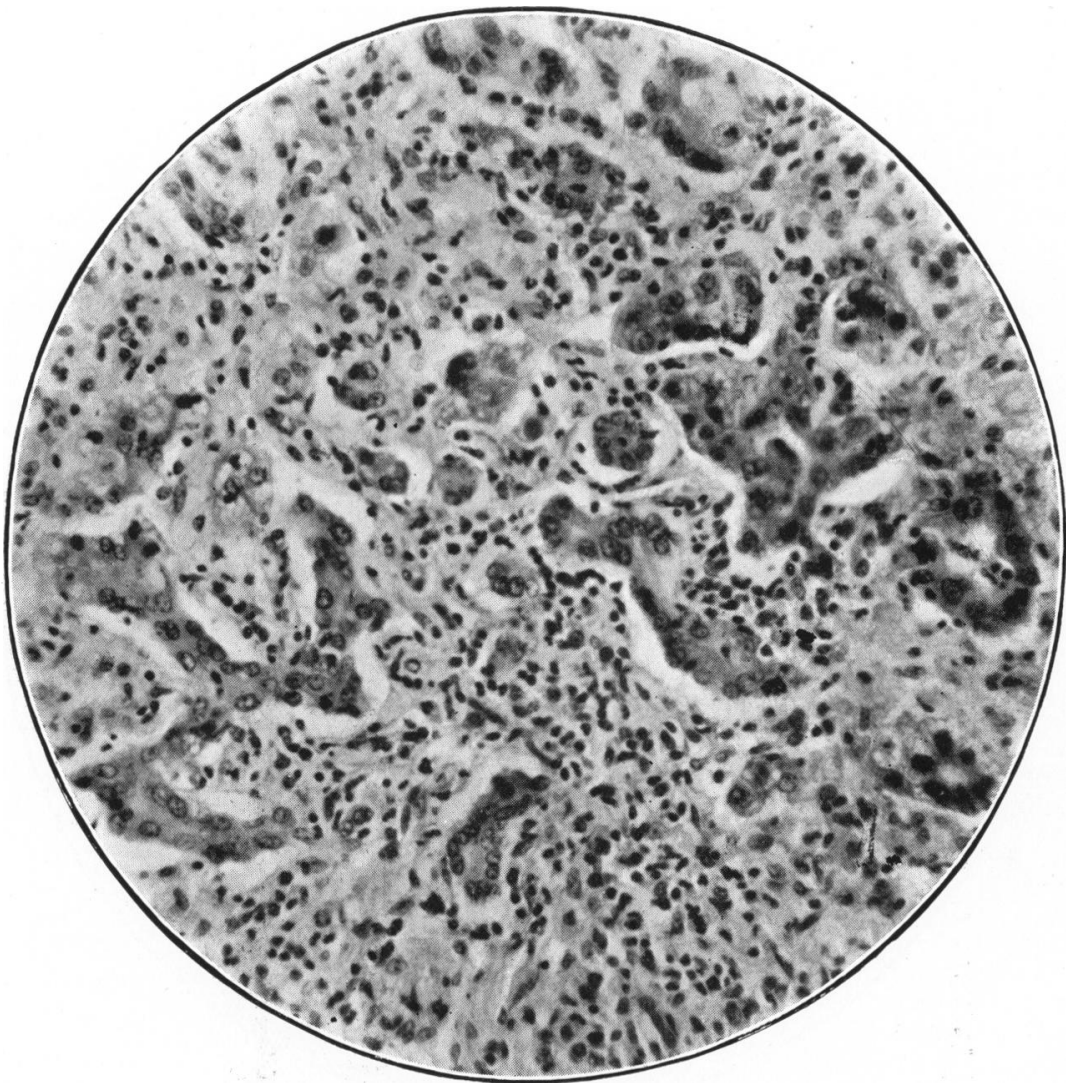

Fı:. 7. Case 2. High power detail.

Heart and blood-vessels normal but bile-stained. Tonsils large with cheesy material in crypts. Iungs, interstitial emphysema, and some areas of collapse; pus in main bronchi. Stomach distended, containing tarry mucus. Upper part of small intestines contained altered blood. In the lower part of the ileum there were congestion and swelling of Peyer's patches. Ridges of mucous membrane in colon and rectum were reddened and there was some ulceration. Pancreas normal. Spleen showed some hyperplasia of the Malpighian bodies. The mesenteric glands were swollen and pink.

Microscopically, the sections showed complete destruction of the parenchyma of the liver, and its replacement by fibro-cellular tissue. New pseudo-bile canaliculi were pres:nt in large numbers but none of them had formed liver cells. There was no attempt at nodular hyperplasia and no sign of fatty degeneration. Under a high power ghosts of dead liver cells with faint granular protoplasm could be distinguished. This extensive destruction seemed to be evenly 
distributed throughout the organ; at no part did there appear to be any normal liver tissue left. These appearances were so similar to those produced by acute poisoning, such as by arsenic or trinitrotoluene, that tests were carried out for the detection of the former substance, but with a negative result.

\section{Discussion.}

Necrosis of the liver in young children, whether acute, sub-acute or chronic, is by no means a rare condition, but it is unusual to find a clear unequivocal cause, and only rarely can the destruction be traced to some definite poison, such as chloroform, arsenic or phosphorus.

The terminology used to describe these cases has been varied and often inappropriate. The word 'atrophy' especially, as used in the terms acute and subacute yellow atrophy, is often incorrect as far as the bulk of the liver is concerned, and inadequate as applied to the liver cells, which have evidently been rapidly destroyed by some chemical or bacterial toxin. 'Necrosis' is a better word. 'Yellow' may indicate the fatty appearance such a liver occasionally presents, or may allude to the bile-staining, which is sometimes a prominent feature; but profound degrees of necrosis may occur without either fatty deposits or retention of bile. The term ' acute' is generally kept for those cases, allied to a similar condition in adults, where there is a fatal conclusion within a few days. 'Sub-acute' is used for cases which last longer than a week, and these merge with a more long-standing condition which Marchand has termed 'nodular hyperplasia,' while these again are indefinitely divided from hepatic 'cirrhosis.' Another title which has some claim to recognition is that of ' toxic hepatitis.'

On reading the detailed accounts of many of the published cases of this kind, it becomes evident that although the morbid anatomy is becoming a well-recognized picture, or group of pictures, the pathogenesis remains obscure.

Morbid histology.-In children, at least, it is unusual to find the liver so completely and quickly overcome by a toxin that there has been no time for the tissues to make some form of reaction or attempt at repair. This, however, may have been of the slightest and only evident on microscopic examination ; on the other hand, if the child has lived for some weeks signs of repair may be obvious to the naked eye in the form of nodules of new liver tissue.

Necrosis is rarely evenly distributed. It occurs patchily, sometimes more in one lobe than another; and in some cases considerable areas have been apparently so much less affected than the surrounding parts that they stand out as islands when the liver is examined at autopsy. At its worst the livercell destruction is complete, so complete that the cell columns have entirely disappeared, or at the most have faint ghostly outlines which may be detected in the stroma. The shrunken framework of the lobule remains, showing new fibro-cellular tissue taking the place of the parenchyma. In the most fulminating cases the lobular arrangement is completely lost and the section looks like a mere mass of granulation tissue, but more often the lobule is roughly defined by the abundant new formation of bile duets which stand out sharply in the section with their deeply staining nuclei. These canaliculi do not con- 
tain bile and have rarely made any connection with the remnants of liver tissue, but they are evidently a first step towards repair, and it has been demonstrated that they are capable of producing new liver cells if given time, and if other means of regeneration have failed. If any liver cells remain they are generally situated in the periphery of the lobule and may show mitotic division. It is from these that hyperplastic nodules develop in those cases which survive the first onslaught of the toxin. Such nodules of new liver tissue form themselves into cell-groups roughly mimicking the original lobular arrangement. They evidently function actively and are often deeply bilestained, perhaps finding some difficulty at first in establishing a free communication with bile-ducts. That they are capable of carrying on liver functions adequately is proved by such cases as Whipple' ${ }^{12}$, which wos found by laparotomy to have had sub-acute yellow atrophy and recovered.

Fatty degeneration is much rarer than complete necrosis, except in cases of chloroform poisoning, but fat is often found in the newly formed cells of the regenerated nodules. Evidence of infection has been suggested by the presence in some cases of abundant leucocytes, and in others of enlarged glands in the portal fissure. An early stage of fibrosis is indicated by new peri-portal fibrous tissue which is often observed in the more protracted cases.

Pathogenesis.- It is interesting to read the accounts of acute and sub-acute liver atrophies in children, of which a great many cases have now been recorded, and to try and trace what was thought to be, or what might have been, the cause in each one. There is extraordinarily little unanimity of opinion about possible causes, and in individual cases there is more often a negative history than any suggestive fact of ætiology. It may be useful, nevertheless, to gather together such facts as we have in an attempt to elucidate a difficult problem.

Klopstock's ${ }^{1}$ patient was a girl of 10 years who died of interstitial pneumonia, having had no symptoms of liver disease during life. The liver showed typical sub-acute yellow atrophy at autopsy.

In connection with this association it may be mentioned here that the present author has under her care a child of seven years old, who suffers from interstitial pneumonia, dating from a primary pneumonia at the age of two. This child has twice had acute exacerbations of the lung condition, accompanied by jaundice and enlarged liver; her lævulose test shows a decidedly faulty liver function. May she not be suffering from sub-acute hepatic necrosis ?

McDonald and Milne 2 described a case in a girl aged 4, lasting 6 weeks. There was no known cause, but the child had an operation for adenoids 2 weeks previously, and had on two occasions suffered from jaundice, once at 2 years and once at 23 years. Nodular hyperplasia was found at autopsy. The two other cases of these authors, a girl aged 7 and a boy aged 7 , showed no evidence of infective or other causes, either in the history or post-mortem findings.

Wilson and Goodpasture ${ }^{3}$ described a case in a boy of 8 complicating cerebellar tumour. The two conditions were not necessarily connected, but a close connection has always been known to exist between liver and brain, as evidenced in the disease known as hepato-lenticular degeneration, and in 
the deep bile-staining of the basal nuclei in cases of icterus gravis neonatorum, so that this association must not altogether be ignored.

Dingwall Fordyce's ${ }^{4}$ patient, a girl aged 6 years and 11 months, had also had a previous attack of jaundice a year before admission. No cause was assigned, but it was recorded that she had left-sided paresis and a squint. However, nothing is mentioned of the central nervous system in the account of the autopsy.

Porter Parkinson's ${ }^{5}$ case was a boy aged 3 years. A staphylococcal pyæmia was found in this case after an illness of 9 weeks.

Woolner's patient ${ }^{6}$, a child aged 19 months, began mildly during an epidemic of jaundice, suddenly developed acute symptoms and died on the 12th day. There were enlarged glands at the portal fissure suggesting an infective origin. This case was similar to Case 2 recorded above, where the patient's brother had had catarrhal jaundice. In this connection it may be mentioned that Cockayne ${ }^{11}$ and others have been convinced of the close connection between epidemic catarrhal jaundice and acute yellow atrophy, between which and sub-acute atrophy there is probably no difference but that of intensity.

C. E. Newman ${ }^{7}$ has described several cases, chiefly in adults, and has pointed out the significance of the association of chloroform and sepsis in preducing necrosis of the liver. One of his fatal cases had a staphylococcal peri-nephric abscess, the second was apparently a simple chloroform poisoning ; but others that survived had both factors, sepsis and chloroform, in their atiology.

B. Roman and D. W. Sherman ${ }^{13}$ recorded a case in a boy of $8 \frac{1}{2}$ months ; duration about 9 days. There was an unusual amount of fatty degeneration in this case, otherwise it showed typical features of necrosis. No cause was assigned.

Griffiths ${ }^{8}$, Hutchison and Paterson ${ }^{9}$, Venn ${ }^{10}$, and others have recorded cases but throw no light upon the cause.

\section{Conclusions.}

It appears that at present the utmost vagueness exists concerning the ætiology of acute and sub-acute hepatic necrosis in children.

Syphilis, although in its acute form it may produce considerable destruction of liver cells and abundance of fibrous tissue, does not quite fit into the histological picture as generally described, and moreover in the majority of reported cases has been definitely absent. Case 1 above showed no sign of syphilis at autopsy, and it can only be concluded that a positive Wassermann reaction after a provocative dose of arsenic is not always proof of syphilis.

Chloroform is a well-known liver poison and has been responsible for many deaths. The histological picture is one of extreme fatty degeneration, rather than of necrosis. Chloroform is not so widely used for anæsthesia as hitherto, and should never be used for septic surgery.

Arsenic, phosphorus and trinitrotoluene are unlikely factors in children's disease, although the first may be administered too freely in congenital syphilis. Other chemicals may play a part. It has been suggested by Professor Hadfield that the colouring matter of sweets may possibly be injurious. 
The infective fevers are causes of hepatic necrosis ; there do not seem to be any cases recorded in children.

Sepsis in some form or another appears from time to time in the records, and it is possible that it might have appeared oftener if a more detailed search had been made. There is scarcely ever any mention of the middle ears and mastoid antra in recorded autopsies; it would be interesting to know if they were examined.

Case 2 reported above had a purulent ear discharge ; at autopsy pus was found in both middle ears. A boy of 8 years now under my care was admitted into the ward with enlarged liver, and jaundice which lasted eight weeks. It is now definitely clearing up since an offensive ear discharge has been treated by radical mastoid operation. It seems most probable that this child has some liver necrosis.

Absence of the mention of otorrhœa in the history means nothing, as so many parents class this as a minor malady, and think no more of taking the child to a doctor for treatment for this condition than for worms or running nose, both of which they consider inherent to childhood.

Whatever the cause, the comparative rarity of the disease would indicate that some other factor than a toxin must be at work in producing such catastrophic destruction in the liver. In the case of pregnant women it is assumed that the liver is already overburdened by the toxins of pregnancy ; in the case of children and adolescents there is possibly some inborn hepatic weakness, but this is a purely theoretical assumption.

Investigation of the literature reveals the most painstaking and minute accounts of the morbid histology in every phase of liver necrosis, but a singular absence of careful enquiry into the history or associated morbid conditions. The symptomatology and morbid anatomy are now well-known, and it would appear that the investigation of further cases would be most usefully directed towards elucidating the cause of the disease.

I am particularly grateful to Professor Hadfield, Dr. Ross, and Dr. Temple Gray for their kindness in having sections prepared and photographed, and for their invaluable advice and expert opinion upon them.

\section{REFERENCES.}

1. Klopstock, F., Virchow's Archir. of path. Anat., Berlin, 1908, CX('TI, 254.

2. MeDonald, S., \& Milne, L. S., Path \& Bact., Edinb., 1909, XIII, 161.

3. Wilson, J. 1)., \& Goodpasture, E. W., Arch. Int. Med., ('hicago, 1927, X I, 377.

4. Fordyce, A. D., Proc. Roy. Sor. Med., Lond., 1909-10, III (Children's Sertion), 1.

5. Parkinson, P., Ibid, 1913-14, VII (Children's Section), 74.

6. Woolner, W., Canada M.A.J., Montreal, 1929, XX, 283.

7. Newman, ('. E., Lancet, Lond., 1928, i, 1012.

8. Griffiths, J., Arch. Pediat., N.Y., 1899, XVI, 330.

9. Hutchison, R., \& Paterson, D., Brit. J. Ch. Dis., Lond., 1924, ХХT, 275.

11. Venn, A., Lanret, Lond., 1884, ii, 191.

11. ('ockayne, E. A., Quart. J. Med., Oxf., 1912, VI, 1.

12. Whipple, A. O., Am. J. Sury., N.Y., 1929, VI, 65.5.

13. Roman, B., \& Sherman, W., Bull. Buff. Gen. Iosp., 1929, VT, 30. 